\title{
Review of the scorpionfly genus Dicerapanorpa Zhong \& Hua (Mecoptera: Panorpidae), with descriptions of two new species
}

\author{
Gui-Lin HU ${ }^{1}$ \& Bao-Zhen HUA ${ }^{2, *}$ \\ ${ }^{1,2}$ Key Laboratory of Plant Protection Resources and Pest Management, Ministry of Education, \\ College of Plant Protection, Northwest A\&F University, Yangling, Shaanxi 712100, China. \\ ${ }^{*}$ Corresponding author: huabzh@nwafu.edu.cn \\ 1Email: huguilin@nwafu.edu.cn \\ ${ }^{1}$ urn:Isid:zoobank.org:author:CAF4242F-C12D-4176-9D0B-A93F54462760 \\ ${ }^{2}$ urn:lsid:zoobank.org:author:C02F1E14-1B20-4B92-BA8F-57937D3D3137
}

\begin{abstract}
The current knowledge of the scorpionfly genus Dicerapanorpa Zhong \& Hua, 2013 is taxonomically reviewed. Two new species of Dicerapanorpa are described and illustrated, increasing the species number of this genus to 20. Dicerapanorpa bifurcata sp. nov. from the Minshan Mountains, Sichuan Province, is characterized by the absence of the paramere basal branch and the elongated mesal branch in males, and the medigynium having a short basal stalk in females. Dicerapanorpa zhengkuni sp. nov. from the Wuling and Miaoling Mountains, Guizhou Province, is distinguishable by the greatly elongated hypovalves, the very short basal branch of the paramere, and the dorsomedially curved lateral branch in males, and the rounded main plate of the medigynium in females. An updated key to species of Dicerapanorpa is presented.
\end{abstract}

Keywords. China, Dicerapanorpa, scorpionfly, taxonomy, species diversity.

Hu G.-L. \& Hua B.-Z. 2020. Review of the scorpionfly genus Dicerapanorpa Zhong \& Hua (Mecoptera: Panorpidae), with descriptions of two new species. European Journal of Taxonomy 711: 1-13.https://doi.org/10.5852/ejt.2020.711

\section{Introduction}

Panorpidae Latreille, 1805 is the most speciose family of Mecoptera Packard, 1886, with more than 480 species in the world (Penny \& Byers 1979; Bicha 2018; Wang \& Hua 2019a, 2019b). They are commonly known as scorpionflies, because their enlarged and recurved male genitalia resemble the stinger of scorpions (Byers \& Thornhill 1983; Dunford \& Somma 2008). Panorpids usually occur in mesic forests in mountainous regions and mainly feed on dead arthropods and vegetative material (Palmer 2010).

Panorpidae currently consists of eight extant genera (Gao \& Hua 2019; Hu et al. 2019c; Wang \& Hua 2019a). Panorpa Linnaeus, 1758 (with ca 260 spp.) is distributed in Asia, Europe and North America. Neopanorpa van der Weele, 1909 (with ca 170 spp.) is limited to the Oriental Region (Wang \& Hua 2017, 2019a, 2019b; Wang \& Hua 2018). Leptopanorpa MacLachlan, 1875 (with 14 spp.) is restricted to Java and Sumatra of Indonesia (Wang \& Hua 2020). The remaining five genera (Sinopanorpa Cai \& 
Hua, 2008, Furcatopanorpa Ma \& Hua, 2011, Dicerapanorpa Zhong \& Hua, 2013, Cerapanorpa Gao, Ma \& Hua, 2016 and Megapanorpa Wang \& Hua, 2019) are endemic to China (Cai et al. 2008; Ma \& Hua 2011; Zhong \& Hua 2013; Hu et al. 2015; Gao et al. 2016; Miao et al. 2019; Wang \& Hua 2019a).

The genus Dicerapanorpa Zhong \& Hua, 2013, erected for the Panorpa diceras group (Cheng 1957), comprises 18 described species to date (Hu \& Hua 2019; Hu et al. 2019a, 2019c). The monophyly of Dicerapanorpa was confirmed by molecular (Hu et al. 2015; Miao et al. 2019) and morphological studies (Ma et al. 2009, 2011, 2012). The genus can be readily recognized by male adults with two finger-like anal horns on the posterior margin of abdominal tergum VI and the trifurcated paramere of genitalia, and females with concealed axis of medigynium (Cheng 1957; Zhong \& Hua 2013). Considerable variations within Dicerapanorpa were found in the wing pattern (Liu et al. 2016), the number of female ovarioles (Hou \& Hua 2008) and the male salivary gland tubes (Ma et al. 2011). The male adult initiates copulation by grasping the female with a notal organ on the posterior margin of the third abdominal tergum and two anal horns on the posterior margin of the sixth tergum, and prolongs copulation by offering salivary masses as nuptial gifts (Zhong et al. 2015). The larvae of Dicerapanorpa are eruciform with annulated processes, reflecting the adaptive significance for fossorial and soil-living habits (Ma et al. 2014; Jiang et al. 2019).

The species of Dicerapanorpa are distributed in the Hengduan Mountains and the adjacent QinlingBashan Mountains (Fig. 1), and can be categorized into two groups (Hu \& Hua 2019; Hu et al. 2019a,

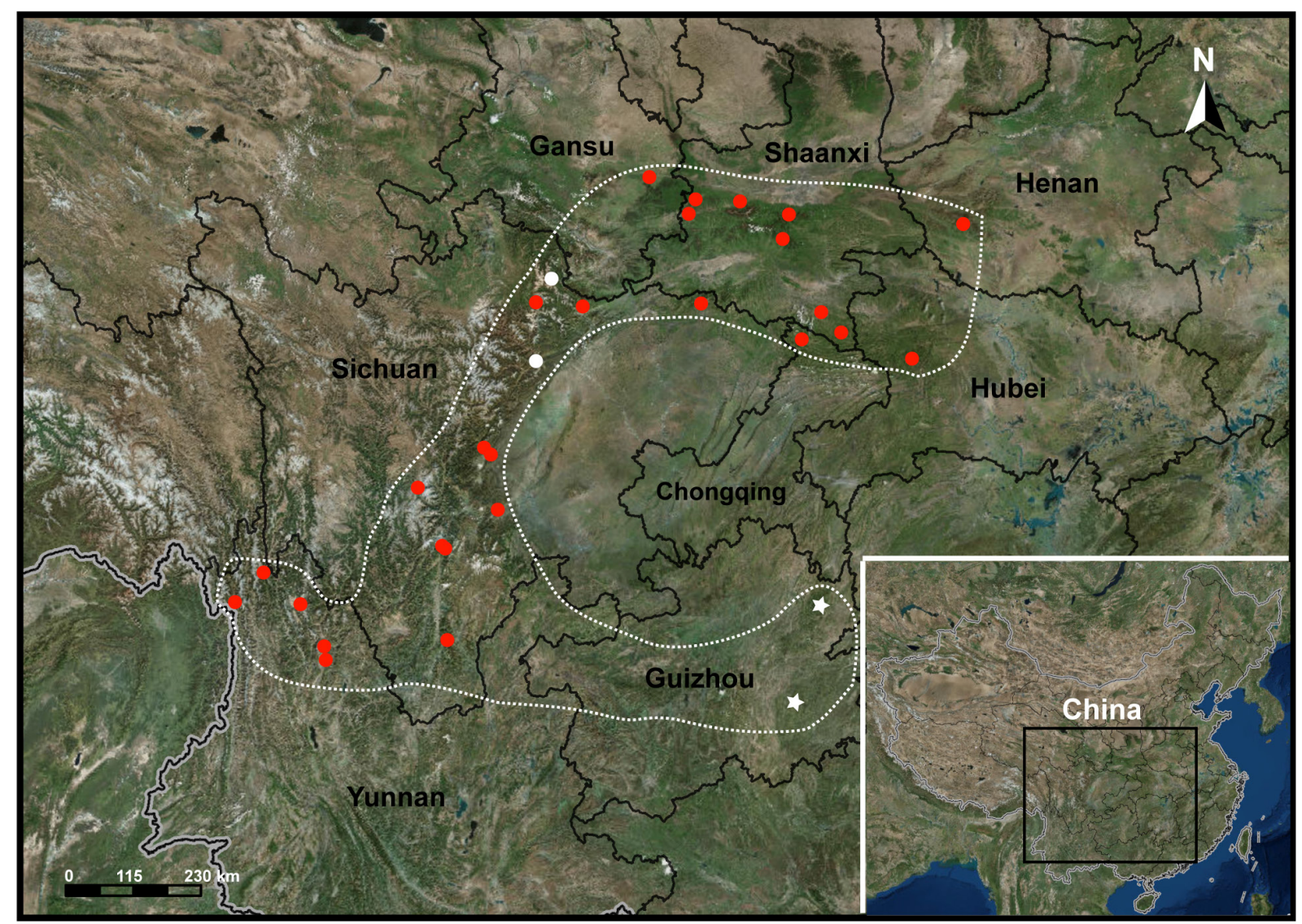

Fig. 1. Geographical distribution of Dicerapanorpa Zhong \& Hua, 2013. The white dots represent the type locality of $D$. bifurcata sp. nov., the white asterisks indicate the type locality of D. zhengkuni sp. nov., and the red dots represent the distribution of the known species of Dicerapanorpa. 
2019b, 2019c). The D. magna group is restricted to the Qinling, Bashan, and Minshan Mountains, and is characterized by the yellowish wing membrane with distinct wing markings and the rostrum without distinct lateral stripes. In contrast, the $D$. diceras group is distributed in the Hengduan Mountains, and is distinguishable by the hyaline wing membrane and the rostrum with two distinct lateral stripes.

In this paper, two new species are described from the Minshan Mountains, Sichuan Province, and the Wuling and Miaoling Mountains, Guizhou Province, China (Fig. 1), respectively, thereby raising the species number of Dicerapanorpa to 20. In addition, we updated the key to species of Dicerapanorpa.

\section{Material and methods}

The specimens were examined using a Nikon SMZ-168 microscope. Female medigynia were macerated in $5 \% \mathrm{NaOH}$ for $3 \mathrm{~min}$, and rinsed with distilled water. Images of habitus were taken with a Nikon D7000 digital camera. Other photographs were taken using an Auto-montage imaging system AxioCam IC attached to a ZEISS SteREO Discovery.V20 stereo microscope. All the images were further processed and assembled with Adobe Photoshop CS6. The length and width of the left wing were measured with a vernier caliper.

All the specimens examined are preserved in $75 \%$ or $100 \%$ ethanol in $-20^{\circ} \mathrm{C}$ freezers. All material is deposited in the Entomological Museum, Northwest A\&F University, Yangling, China (NWAU).

\section{Abbreviations}

A1 = first abdominal segment (and so forth for other segments)

$\mathrm{T} 1=$ first tergum (and so forth for other terga)

\section{Abbreviations for morphological terms used in figures}

$$
\begin{aligned}
\mathrm{ae} & =\text { aedeagus } \\
\mathrm{ax} & =\text { axis } \\
\mathrm{bb} & =\text { basal branch } \\
\mathrm{bp} & =\text { basal process } \\
\mathrm{ep} & =\text { epandrium } \\
\mathrm{gcx} & =\text { gonocoxite } \\
\mathrm{gs} & =\text { gonostylus } \\
\mathrm{hv} & =\text { hypovalve } \\
\mathrm{b} & =\text { lateral branch } \\
\mathrm{mb} & =\text { mesal branch } \\
\mathrm{mp} & =\text { main plate } \\
\mathrm{mt} & =\text { median tooth } \\
\mathrm{pa} & =\text { posterior arm } \\
\mathrm{sgp} & =\text { subgenital plate }
\end{aligned}
$$

\section{Results}

\section{Taxonomic treatments}

Class Insecta Linnaeus, 1758

Order Mecoptera Packard, 1886

Family Panorpidae Latreille, 1805

Genus Dicerapanorpa Zhong \& Hua, 2013

Dicerapanorpa Zhong \& Hua, 2013: 1021. Type species: Panorpa magna Chou, 1981 [by original designation]. 
Dicerapanorpa bifurcata $\mathrm{Hu} \&$ Hua sp. nov. urn:1sid:zoobank.org:act:E02C50F8-920B-4A40-B7BD-EA4666930497

Figs $2-3$

\section{Diagnosis}

This species can be readily recognized by the following characters: basal branch of male paramere absent; mesal branches elongated, convergent distally, and extending to the median tooth of gonostylus; lateral branch curved semicircularly at base and convergent at apex, exceeding basal process of gonostylus (Figs 2D, 3A-B); and female medigynium strongly folded ventrally on each side, bearing a short basal stalk, with rounded main plate beneath the basal stalk (Figs 2F, 3C).

\section{Etymology}

The specific epithet refers to the bifurcated paramere of the male genitalia.

\section{Type material}

\section{Holotype}

CHINA - Sichuan Province - ${ }^{\circ}$; Pingwu County, Wanglang Nature Reserve; $32.92^{\circ}$ N, $104.16^{\circ}$ E; 2500 m a.s.1.; 2 Jun. 2018; Kai Gao leg.; NWAU.

A
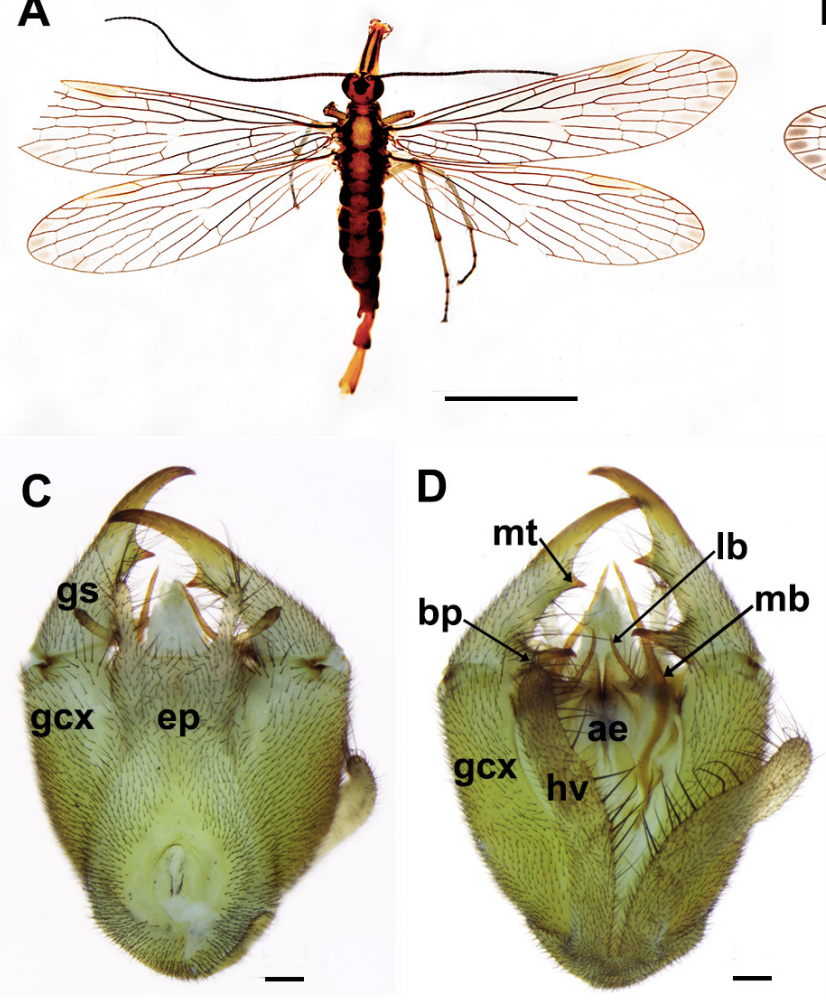

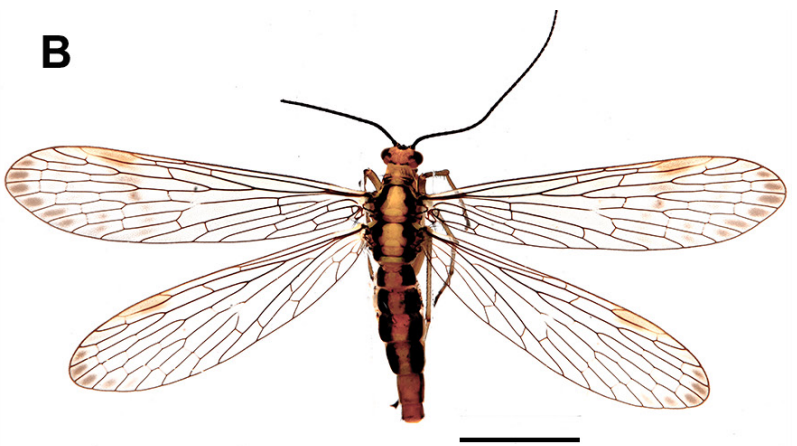

E

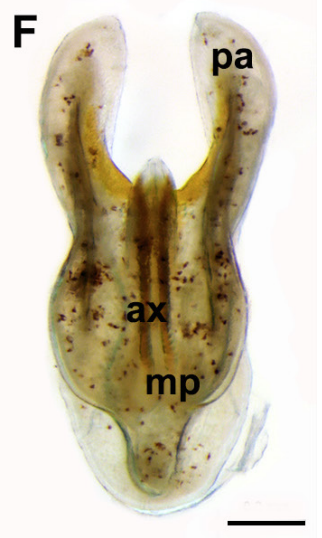

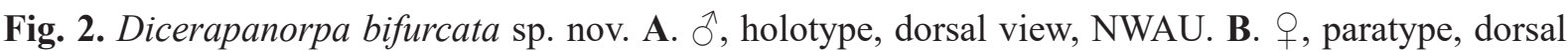
view, NWAU. C-D. $\widehat{\partial}$, genital bulb in dorsal and ventral views, respectively. E. $\%$, subgenital plate, ventral view. F. 9 , medigynium, ventral view. Scale bars: $\mathrm{A}-\mathrm{B}=5.0 \mathrm{~mm} ; \mathrm{C}-\mathrm{F}=0.2 \mathrm{~mm}$. 


\section{Paratypes}

CHINA - Sichuan Province• $2 \widehat{\jmath}, 14$ $+\circ$; same data as for the holotype; Kai Gao and Yu-Ru Yang leg.; NWAU • 1 ○; Maoxian County, Tudiling; $31.71^{\circ} \mathrm{N}, 103.92^{\circ} \mathrm{E}$; $2500 \mathrm{~m}$ a.s.1.; 21 May 2018; Kai Gao leg.; NWAU.

\section{Description}

Male

HEAD. Head mostly yellow. Rostrum faint yellow, with pair of blackish longitudinal stripes laterally. Maxillary and labial palps yellowish brown, distal segment dark brown. Antenna black brown. Ocellar triangle black (Fig. 2A).

THORAX. Pronotum yellow, with short black setae along anterior margin and two black longitudinal stripes laterally. Meso- and metanotum pale yellow with black longitudinal stripe on each side. Pleura and sterna yellow. Legs pale brown, distal tarsi dark brown (Fig. 2A).

WING. Forewing length $13.4 \mathrm{~mm}$, width $3.4 \mathrm{~mm}$; membrane hyaline; apical and pterostigmal bands reduced to discontinuous spots, other markings absent. Hindwing length $12.5 \mathrm{~mm}$, width $3.3 \mathrm{~mm}$, similar to forewing in coloration and pattern (Fig. 2A).

ABDOMEN. T1-T5 yellow, with two black longitudinal stripes laterally. Notal organ on T3 slightly developed, semicircular, bearing numerous stout setae posteriorly. Post-notal organ on T4 pointed, projecting forward. Sterna and pleura yellowish. A6 yellowish brown, bearing two short digitate anal horns on posterior margin. A7 yellowish, elongated, constricted basally, abruptly dilated distally. A8 yellow, evenly broadening toward apex (Fig. 2A).

Genitalia. Genital bulb ovoid, yellowish brown. Epandrium (tergum IX) broad basally, constricted at distal third, terminating with deep trapezoidal emargination between two parallel setose lobes (Fig. 2C). Hypovalves broad, divergent apically, covered with long black bristles along inner margin, reaching apex of gonocoxite. Gonostylus shorter than gonocoxite, smoothly curved convergently; basal process gradually narrowing toward acute tip; median tooth subtriangular (Figs 2D, 3A). Basal branches
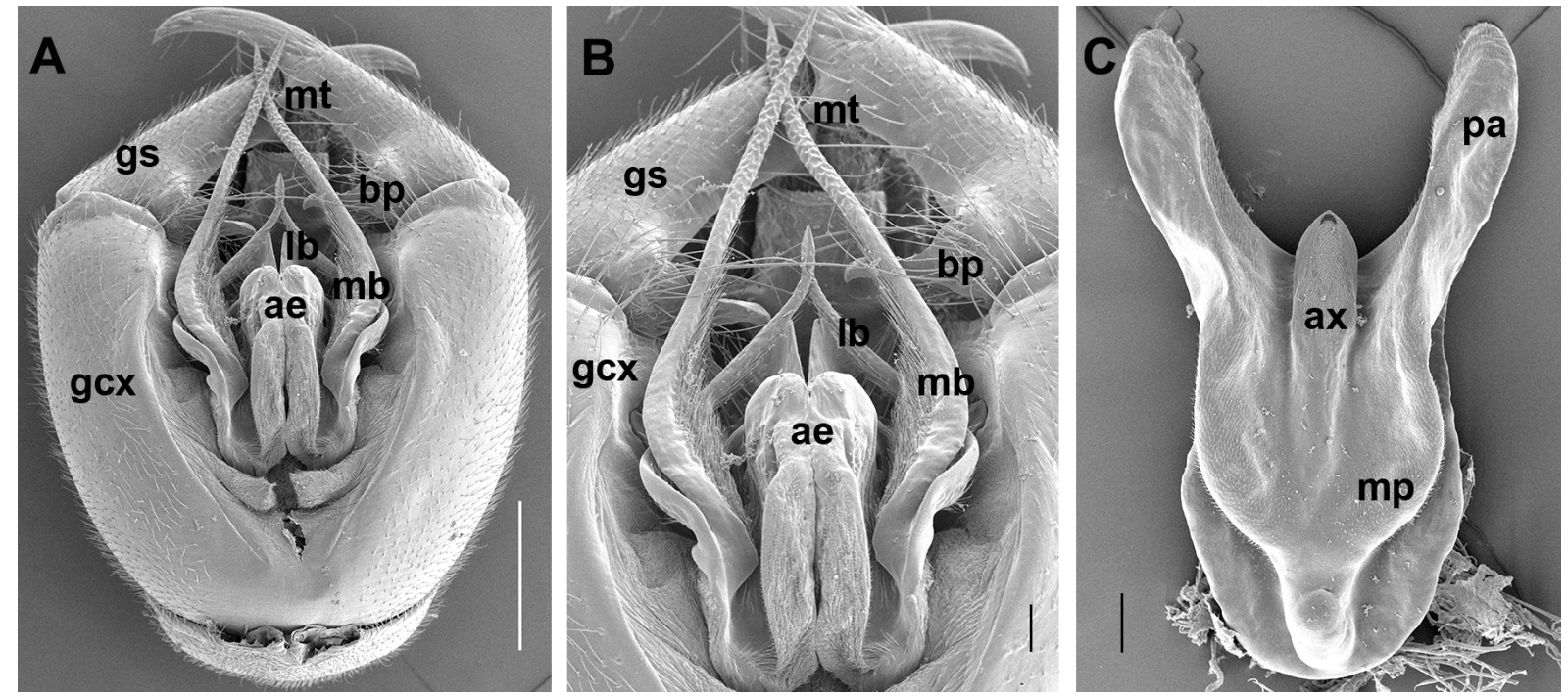

Fig. 3. Scanning electron micrographs of genitalia of Dicerapanorpa bifurcata sp. nov. A. $\widehat{\jmath}$, genitalia in ventral view, with hypandrium removed. B. Magnification of A. C., , medigynium, ventral view. Scale bars: $\mathrm{A}=0.5 \mathrm{~mm}$; $\mathrm{B}-\mathrm{C}=0.1 \mathrm{~mm}$. 
of parameres absent; mesal branches elongated, curved convergently, extending to median tooth of gonostylus; lateral branch curved semicircularly near base and convergent at apex, slightly exceeding basal process of gonostylus (Fig. 3B). Ventral valves of aedeagus short and slender; dorsal valves separated apically, greatly elongated, reaching apex of gonocoxite (Fig. 3B).

\section{Female}

HEAD, THORAX AND ABDOMEN. Similar to males in general appearance (Fig. 2B). Forewing length 14.5$15.8 \mathrm{~mm}$, width $3.9-4.1 \mathrm{~mm}$; hindwing length $13.3-14.4 \mathrm{~mm}$, width $3.9-4.1 \mathrm{~mm}$.

Genitalia. Subgenital plate trapezoidal, terminating in ligulate process, covered with long bristles caudally (Fig. 2E). Medigynium strongly folded ventrally on each side, bearing short stalk at base, with round main plate beneath basal stalk. Posterior arm stout, nearly half as long as main plate. Axis concealed in main plate, slightly protruding apically (Figs 2F, 3C).

\section{Distribution}

Minshan Mountains, Sichuan Province, China (Fig. 1).

Dicerapanorpa zhengkuni Hu \& Hua sp. nov. urn:lsid:zoobank.org:act:D002EF64-9B01-4A06-B46A-0514533684CF

Figs 4-5

\section{Diagnosis}

This new species can be readily differentiated from its congeners by the following features: wings dusky hyaline, pterostigmal band with broad basal branch, gradually narrowing toward posterior margin, apical band greatly reduced (Fig. 4A-B); male hypovalve greatly elongated, extending far beyond basal process of gonostylus (Fig. 4H); basal branches of male paramere extremely short, mesal branches semicircular basally and convergent apically, lateral branches curved to dorsal side basally (Fig. 5A-B); and main plate of female medigynium rounded, folded ventrally into a circular plate (Fig. 5C).

\section{Etymology}

The specific name is dedicated to Mr. Zheng-Kun Hu for his generous help to this study.

\section{Type material}

\section{Holotype}

CHINA - Guizhou Province • ${ }^{\wedge}$; Jiangkou County, Fanjinshan Nature Reserve; $27.91^{\circ} \mathrm{N}, 108.65^{\circ} \mathrm{E}$; 2200 m a.s.1.; 5 Jun. 2018; Gui-Lin Hu leg.; NWAU.

\section{Paratypes}

CHINA - Guizhou Province $13 \hat{\partial} \hat{\partial}, 65$ q $q$; same data as for the holotype; Gui-Lin Hu \& Ning Li leg.; NWAU • 2 đo ${ }^{\Uparrow}, 1$ q; Leishan County, Leigongshan Nature Reserve; $26.37^{\circ} \mathrm{N}, 108.17^{\circ} \mathrm{E} ; 1600 \mathrm{~m}$ a.s.1.; 28 May 2018; Gui-Lin Hu and Ning Li leg.; NWAU.

\section{Description}

\section{Male}

HEAD. Head mostly yellow. Rostrum yellow with pair of blackish lateral longitudinal stripes. Maxillary and labial palps yellowish brown, distal segment dark brown. Antenna black. Ocellar triangle black (Fig. 4A, C). 
Thorax. Pronotum yellow with several stout setae along anterior margin and two black longitudinal stripes on lateral sides. Meso- and metanotum yellow, with black longitudinal stripe along each side. Pleura pale yellow. Legs brown with tarsomere darkening toward apex (Fig. 4A).

WINGS. Forewing length $15.0 \mathrm{~mm}$, width $4.0 \mathrm{~mm}$. Wing dusky hyaline with markings greatly reduced. Hindwing length $13.9 \mathrm{~mm}$, width $3.9 \mathrm{~mm}$, similar to forewing in color and pattern (Fig. 4A).

ABDomen. T1-T5 yellowish with two black longitudinal stripes laterally. Sterna and pleura yellow. Notal organ on T3 semicircular, prominent, bearing numerous setae posteriorly. Post-notal organ on T4

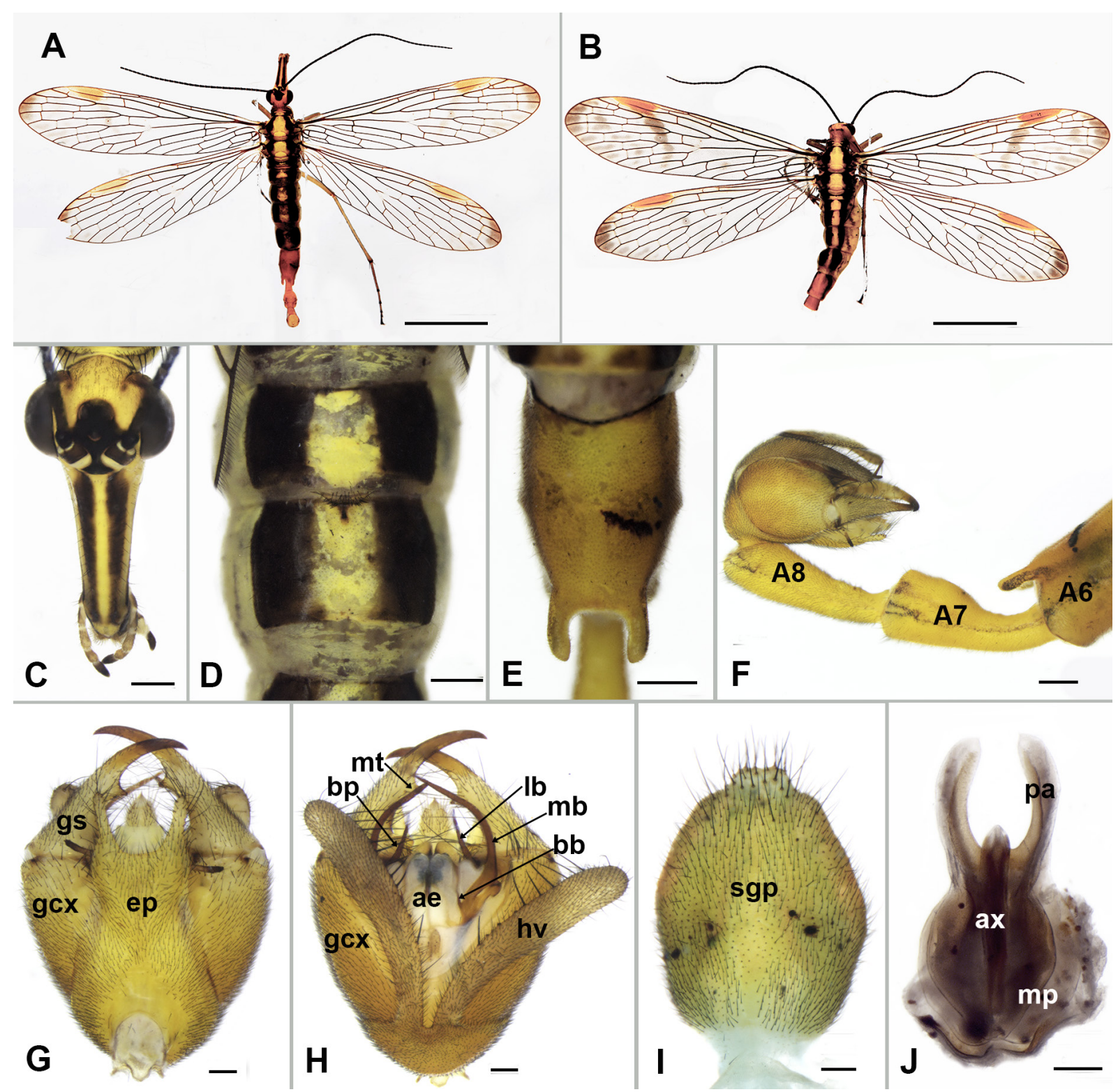

Fig. 4. Dicerapanorpa zhengkuni sp. nov. A. $\widehat{\jmath}$, holotype, dorsal view, NWAU. B. $\uparrow$, paratype, dorsal view, NWAU. C. Head, frontal view. D. Oे, abdominal segments III and IV, showing the notal organ, dorsal view. E. Anal horns, dorsal view. F. $\hat{\jmath}$, A6-A8, lateral view. G-H. $\hat{\jmath}$, genital bulb in dorsal and ventral views, respectively. I. + , subgenital plate, ventral view. J. + , medigynium, ventral view. Scale bars: $\mathrm{A}-\mathrm{B}=5.0 \mathrm{~mm}$; $\mathrm{C}-\mathrm{F}=0.5 \mathrm{~mm}$; G-J $=0.2 \mathrm{~mm}$. 
short, hook-shaped, protruding forward (Fig. 4D). A6 uniformly yellowish brown, with pair of parallel finger-like anal horns on posterior margin (Fig. 4E). A7 elongated, constricted at basal half and abruptly dilated at distal half. A8 similar to A7, but gradually broadened distally (Fig. 4F).

GENITALIA. Genital bulb ovoid, yellowish brown. Epandrium broad basally, tapering toward apex, with deep broad U-shaped terminal emargination between two parallel digital processes, almost reaching median tooth of gonostylus (Fig. 4G). Hypovalve greatly elongated, broad, with long bristles along inner margin, extending far beyond basal process of gonostylus (Fig. 4H). Gonostylus shorter than gonocoxite, bearing well-developed basal process and subtriangular median tooth (Figs 4H, 5A). Paramere trifurcated: basal branches very short, pointed; mesal branches elongated, curved convergently at apex, extending to median tooth of gonostylus; lateral branches sinuated to dorsal side basally, parallel apically, exceeding basal process of gonostylus. Aedeagus with paired ventral and dorsal valves: ventral valves short, narrow; dorsal valves sclerotized, separated distally, nearly reaching basal process of gonostylus (Figs 4H, 5B).

\section{Female}

HEAD, THORAX AND ABDOMEN. Similar to males in general appearance. Wing dusky hyaline, pterostigmal band with broad basal branch and reduced distal branch, extending to vein $\mathrm{M}_{4}$; apical band grayish brown, greatly reduced, discontinuous. Forewing length $15.8-16.9 \mathrm{~mm}$, width $3.9-4.5 \mathrm{~mm}$; hindwing length 14.5-15.2 mm, width 3.9-4.3 mm (Fig. 4B).

Genitalia. Subgenital plate ovoid, gradually tapering toward apex, terminating in truncated ligulate process, covered with long bristles caudally (Fig. 4I). Medigynium with main plate strongly sclerotized and ovoid, folded ventrally into round plate. Posterior arms smoothly curved inward, shorter than main plate. Axis almost entirely concealed in main plate, slightly pointed apically (Figs 4J, 5C).
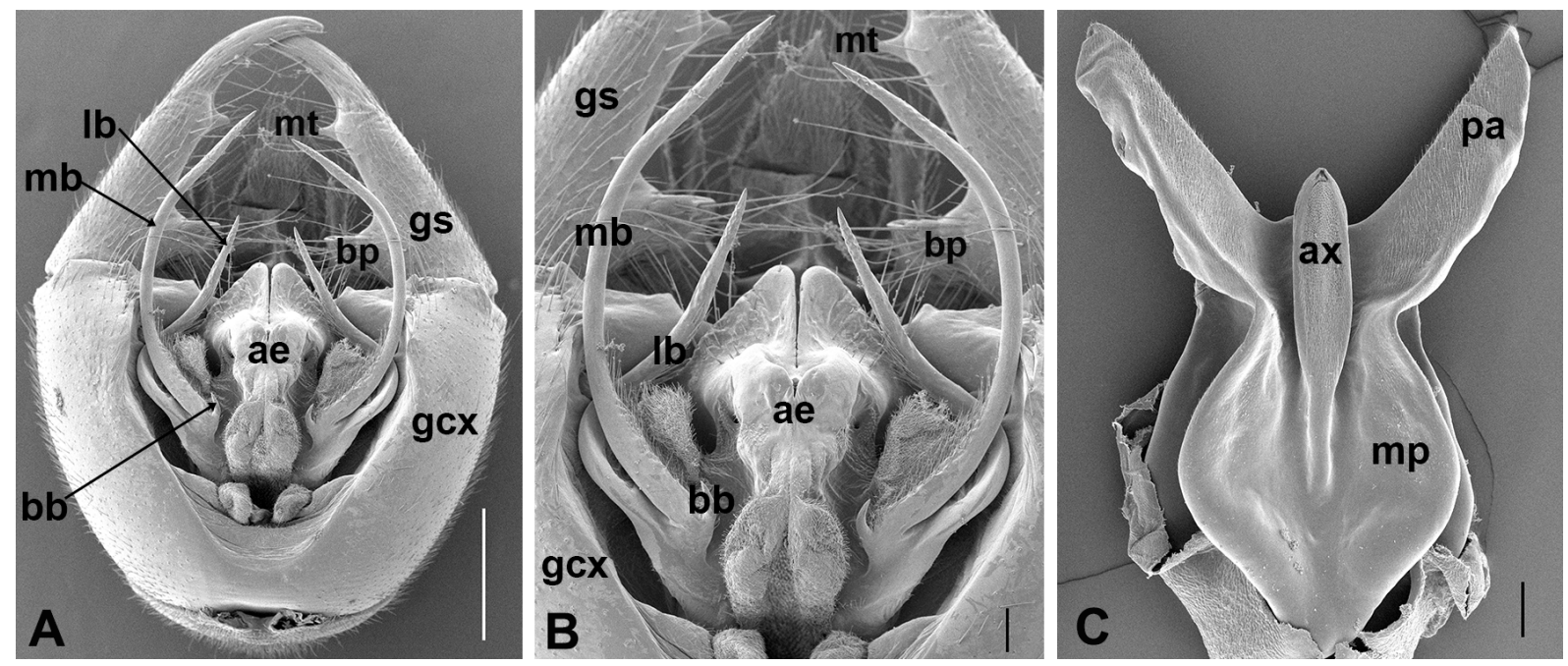

Fig. 5. Scanning electron micrographs of genitalia of Dicerapanorpa zhengkuni sp. nov. A. $\hat{\jmath}$, genitalia in ventral view, with hypandrium removed. B. Magnification of A. C. + , medigynium, ventral view. Scale bars: $\mathrm{A}=0.5 \mathrm{~mm}$; $\mathrm{B}-\mathrm{C}=0.1 \mathrm{~mm}$. 


\section{Distribution}

Wuling and Miaoling Mountains, Guizhou Province, China (Fig. 1).

\section{Key to species of Dicerapanorpa (males)}

(updated from $\mathrm{Hu}$ et al. 2019c)

1. Wings yellowish with distinct dark brown markings, apical band broad, enclosing a large hyaline window; pterostigmal band complete, with a broad basal branch and a separated narrow distal branch; basal band complete, across the wing or slightly reduced; rostrum with indistinct black longitudinal stripes

- Wings hyaline with indistinct markings, apical, pterostigmal and basal bands extremely reduced; rostrum with two distinct black longitudinal stripes

2. Basal branch of paramere not reaching apex of ventral valve of aedeagus; mesal branch short, not reaching median tooth of gonostylus

- Basal branch of paramere nearly reaching apex of ventral valve of aedeagus; mesal branch slender and elongated, extending to median tooth of gonostylus

D. baiyunshana Zhong \& Hua, 2013

3. Mesal branches of paramere curved convergently, more than twice the length of basal branches ....

- Mesal branches of paramere parallel, nearly twice the length of basal branches

D. shennongensis Zhong \& Hua, 2013

4. Basal branch of paramere shorter, less than half the length of lateral branch; ventral valve of aedeagus broad and short

- Basal branch of paramere longer, more than half the length of lateral branch; ventral valve of aedeagus narrow and long

D. hualongshana $\mathrm{Hu} \& \mathrm{Hua}, 2019$

5. Genital bulb narrow and elliptical; basal branch of paramere straight or curved nearly perpendicularly D. magna (Chou, 1981)

- Genital bulb broad and spherical; basal branch of paramere hook-shaped

D. minshana Hu \& Hua, 2019

6. Hypovalve narrow basally and greatly broadened distally ......................................................... 7

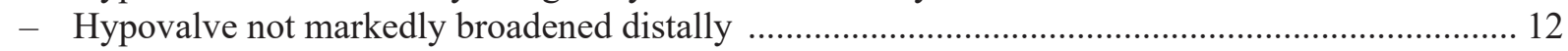

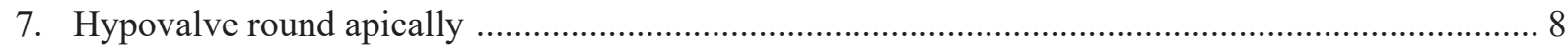

- Hypovalve truncated apically ................................................... D. stotzneri (Esben-Petersen, 1934)

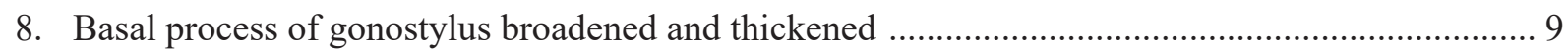

- Basal process of gonostylus narrow and long, pointed distally ....................................................11

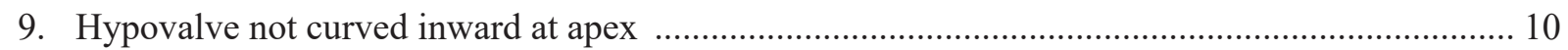

- Hypovalve curved inward at apex; all branches of paramere exceeding apex of gonocoxite; basal branch straight, mesal and lateral branches greatly curved inward

D. tenuis $\mathrm{Hu}$, Wang \& Hua, 2019

10. Genital bulb slender and elliptical; all branches of paramere broadened basally and narrowed distally, reaching or exceeding basal process of gonostylus; lateral branch slightly curved inward; aedeagus narrow

D. diceras (MacLachlan, 1894)

- Genital bulb broad and spherical; basal branch of paramere very short; mesal branch tapering toward apex, reaching median tooth of gonostylus; lateral branches curved perpendicularly, convergent 
at basal two-thirds and parallel at apical one-third, extending over median tooth of gonostylus, aedeagus broad

D. tanae Hu, Wang \& Hua, 2019

11. Dorsal valves of aedeagus narrow and sharply angular at apex; lateral branch of paramere convergent apically, reaching basal process of gonostylus

D. luojishana Hu \& Hua, 2019

- Dorsal valves of aedeagus broad and rounded at apex; lateral branch of paramere curved semicircularly at basal two-thirds, nearly parallel at distal one-third, extending far beyond basal process of gonostylus

D. lativalva Hu \& Hua, 2019

12. Paramere trifurcated with basal branch short or long

- Paramere bifurcated with basal branch absent; mesal branches convergent distally, reaching median tooth of gonostylus; lateral branch conspicuously sinuated toward dorsal side, intersected apically; dorsal valves of aedeagus divergent apically, reaching apex of gonocoxite

D. bifurcata sp. nov.

13. Basal branch of paramere extremely short, less than one-third the length of mesal branch, straight or hooked ....

- Basal branch of paramere more than one-third the length of mesal branch, straight or curved ..... 15

14. Wings hyaline without markings; hypovalve not exceeding basal process of gonostylus; basal branch of paramere hooked, mesal branches slightly curved basally and nearly parallel distally; lateral branches curved semi-circularly

D. kimminsi (Carpenter, 1948)

- Wings hyaline with incomplete black pterostigma and apical bands; hypovalve elongated, extending beyond basal process of gonostylus; basal branches of paramere straight, mesal branches curved semi-circularly basally and convergent apically, lateral branches sinuated toward dorsal side

D. zhengkuni sp. nov.

15. Ventral valve of aedeagus not extending to apex of gonocoxite. 16

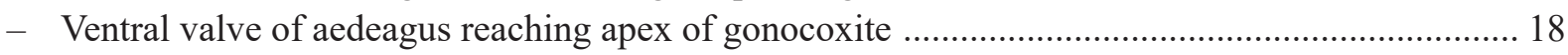

16. Hypovalve extending to apex of gonocoxite 17

- Hypovalve not reaching apex of gonocoxite; basal branches of paramere parallel; mesal branches convergent apically, extending to basal process of gonostylus; lateral branches slightly curved

D. triclada (Qian \& Zhou, 2001)

17. Basal branch of paramere elongated, exceeding basal process of gonostylus; mesal branches straight and parallel, reaching median tooth of gonostylus; lateral branch straight, not reaching apex of gonocoxite

D. macula Hu, Wang \& Hua, 2019

- Basal branch of paramere not reaching basal process of gonostylus; mesal branches straight, intersected distally, exceeding median tooth of gonostylus; lateral branches convergent distally, reaching basal process of gonostylus

D. zhongdianensis $\mathrm{Hu}$, Wang \& Hua, 2019

18. Lateral branch of paramere not bifurcated

- Lateral branch of paramere bifurcated distally; basal branch nearly reaching apex of gonocoxite; mesal branches slightly curved basally and parallel distally, exceeding median tooth of gonostylus

D. tjederi (Carpenter, 1938)

19. Terminal emargination of epandrium shallow and rounded; basal branch of paramere nearly as long as lateral branch, reaching apex of gonocoxite; mesal branch elongated, extending to median tooth of gonostylus

D. deqenensis $\mathrm{Hu}$, Wang \& Hua, 2019 
- Terminal emargination of epandrium deep and trapezoidal; basal branch of paramere curved inward basally and parallel distally, not reaching apex of gonocoxite; mesal and lateral branches convergent apically, reaching basal process of gonostylus

D. yijunae Hu \& Hua, 2019

\section{Discussion}

In this study, we reviewed the descriptions of all the known species of Dicerapanorpa, and found that the so-called D. stotzneri (Esben-Petersen, 1934) in Zhong \& Hua (2013) was very likely a misidentification, because the female medigynium differs from the original descriptions (Esben-Petersen 1934; Tjederi 1936; Cheng 1957). In fact, the figures of the female medigynium of D. stotzneri by Zhong \& Hua (2013: fig. 12B-D) are more similar to those of D. yijunae Hu \& Hua, 2019 (Hu \& Hua 2019: fig. 3D).

The genus Dicerapanorpa was previously known to be restricted to the Hengduan and Qinling-Bashan Mountains. The distribution of D. zhengkuni sp. nov. in the Guizhou Plateau is likely an important biogeographical event. In this case, the genus Dicerapanorpa exhibits an intriguing circular distribution pattern around the Sichuan Basin. The mechanisms of this distribution pattern and associated species diversification in Dicerapanorpa should be an interesting topic to study in the future.

\section{Acknowledgements}

We thank Leigongshan, Fanjinshan and Wanglang National Nature Reserves for assistance in field collection. We are also grateful to Zheng-Kun Hu, Ning Li, Yu-Ru Yang and Kai Gao for collecting specimens, and Ji-Shen Wang for taking pictures. This research was funded by the National Natural Science Foundation of China (Grant no. 31672341).

\section{References}

Bicha W.J. 2018. Biodiversity of Mecoptera. In: Foottit R.G. \& Adler P.H. (eds) Insect Biodiversity: Science and Society, II: 705-720. John Wiley \& Sons, Hoboken.

https://doi.org/10.1002/9781118945582.ch23

Byers G.W. \& Thornhill R. 1983. Biology of the Mecoptera. Annual Review of Entomology 28: 203228. https://doi.org/10.1146/annurev.en.28.010183.001223

Cai L.J., Huang P.Y. \& Hua B.Z. 2008. Sinopanorpa, a new genus of Panorpidae (Mecoptera) from the Oriental China with descriptions of two new species. Zootaxa 1941: 43-54.

https://doi.org/10.11646/zootaxa.1941.1.4

Cheng F.Y. 1957. Revision of the Chinese Mecoptera. Bulletin of the Museum of Comparative Zoology 116: $1-118$.

Dunford J.C. \& Somma L.A. 2008. Scorpionflies (Mecoptera). In: Capinera J.L. (ed.) Encyclopedia of Entomology: 3304-3310. Springer Netherlands, Berlin.

Esben-Petersen P. 1934. Two new species of Panorpa Linn. (Mecoptera). Videnskabelige Meddelelser Dansk Naturhistorisk Forening 97: 211-213.

Gao K. \& Hua B.Z. 2019. Revision of the genus Cerapanorpa (Mecoptera: Panorpidae) with descriptions of four new species. European Journal of Taxonomy 537: 1-23. https://doi.org/10.5852/ejt.2019.537

Gao C., Ma N. \& Hua B.Z. 2016. Cerapanorpa, a new genus of Panorpidae (Insecta: Mecoptera) with descriptions of three new species. Zootaxa 4158: 93-104. https://doi.org/10.11646/zootaxa.4158.1.5

Hou X.Y. \& Hua B.Z. 2008. Structures of the female reproductive systems in Panorpidae (Mecoptera) with remarks on their taxonomic significance. Acta Zootaxonomica Sinica 33: 427-434. 
Hu G.L. \& Hua B.Z. 2019. Two new species of the genus Dicerapanorpa (Mecoptera: Panorpidae) from Sichuan, China. Entomotaxonomia 41: 73-79.

Hu G.L., Yan G., Xu H. \& Hua B.Z. 2015. Molecular phylogeny of Panorpidae (Insecta: Mecoptera) based on mitochondrial and nuclear genes. Molecular Phylogenetics and Evolution 85: 22-31.

https://doi.org/10.1016/j.ympev.2015.01.009

Hu G.L., Gao K., Wang J.S. \& Hua B.Z. 2019a. Molecular phylogeny and species delimitation of the genus Dicerapanorpa (Mecoptera: Panorpidae). Zoological Journal of the Linnean Society 187: 11731195. https://doi.org/10.1093/zoolinnean/zlz059

Hu G.L., Hua Y., Hebert P.D.N. \& Hua B.Z. 2019b. Evolutionary history of the scorpionfly Dicerapanorpa magna (Mecoptera, Panorpidae). Zoologica Scripta 48: 93-105. https://doi.org/10.1111/zsc.12326

Hu G.L., Wang J.S. \& Hua B.Z. 2019c. Five new species of Dicerapanorpa Zhong \& Hua (Mecoptera, Panorpidae) from Yunnan, China. Journal of Asia-Pacific Entomology 22: 159-166.

https://doi.org/10.1016/j.aspen.2018.10.020

Jiang L., Hua Y., Hu G.L. \& Hua B.Z. 2019. Habitat divergence shapes the morphological diversity of larval insects: insights from scorpionflies. Scientific Report 9: 12708.

https://doi.org/10.1038/s41598-019-49211-z

Liu M., Ma N. \& Hua B.Z. 2016. Intraspecific morphological variation of the scorpionfly Dicerapanorpa magna (Chou) (Mecoptera: Panorpidae) based on geometric morphometric analysis of wings. Contributions to Zoology 85: 1-11. https://doi.org/10.1163/18759866-08501001

Ma N. \& Hua B.Z. 2011. Furcatopanorpa, a new genus of Panorpidae (Mecoptera) from China. Journal of Natural History 45: 2251-2261. https://doi.org/10.1080/00222933.2011.595517

Ma N., Cai L.J. \& Hua B.Z. 2009. Comparative morphology of the eggs in some Panorpidae (Mecoptera) and their systematic implication. Systematics and Biodiversity 7: 403-417.

https://doi.org/10.1017/S1477200009990107

Ma N., Liu S.Y. \& Hua B.Z. 2011. Morphological diversity of male salivary glands in Panorpidae (Mecoptera). European Journal of Entomology 108: 493-499. https://doi.org/10.14411/eje.2011.064

Ma N., Zhong W., Gao Q.H. \& Hua B.Z. 2012. Female genital plate diversity and phylogenetic analyses of East Asian Panorpidae (Mecoptera). Systematics and Biodiversity 10: 159-178.

https://doi.org/10.1080/14772000.2012.683459

Ma N., Chen H.M. \& Hua B.Z. 2014. Larval morphology of the scorpionfly Dicerapanorpa magna (Chou) (Mecoptera: Panorpidae) and its adaptive significance. Zoologischer Anzeiger 253: 216-224. https://doi.org/10.1016/j.jcz.2013.10.002

Miao Y., Wang J.S. \& Hua B.Z. 2019. Molecular phylogeny of the scorpionflies Panorpidae (Insecta: Mecoptera) and chromosomal evolution. Cladistics 35: 385-400. https://doi.org/10.1111/cla.12357

Palmer C.M. 2010. Diversity of feeding strategies in adult Mecoptera. Terrestrial Arthropod Reviews 3: 111-128. https://doi.org/10.1163/187498310X519716

Penny N.D. \& Byers G.W. 1979. A check-list of the Mecoptera of the world. Acta Amazonica 9: 365388. https://doi.org/10.1590/1809-43921979092365

Tjederi B. 1936. Schwedisch-Chinesische wissenschaftliche Expedition nach den nordwestlichen Provinzen Chinas, 51. Arkiv för Zoologi 27A: 1-14.

Wang J.S. \& Hua B.Z. 2017. An annotated checklist of the Chinese Mecoptera with description of male Panorpa guttata Navás, 1908. Entomotaxonomia 39: 24-42.

https://doi.org/10.11680/entomotax.2017003 
Wang J.S. \& Hua B.Z. 2019a. Megapanorpa, a new genus with a single anal horn in males from Oriental China (Mecoptera: Panorpidae). Entomological Science 22: 64-79. https://doi.org/10.1111/ens. 12336

Wang J.S. \& Hua B.Z. 2019b. Taxonomy of the genus Neopanorpa van der Weele, 1909 (Mecoptera, Panorpidae) from the Oriental Region, with the description of two new species. European Journal of Taxonomy 543: 1-17. https://doi.org/10.5852/ejt.2019.543

Wang J.S. \& Hua B.Z. 2020. Taxonomic revision and phylogenetic analysis of the enigmatic scorpionfly genus Leptopanorpa MacLachlan (Mecoptera: Panorpidae). Journal of Zoological Systematics and Evolutionary Research. https://doi.org/10.1111/jzs.12363

Wang M. \& Hua B.Z. 2018. High species diversity of the genus Neopanorpa in Yunnan Province, China. Zootaxa 4483: 036-066. https://doi.org/10.11646/zootaxa.4483.1.2

Zhong W. \& Hua B.Z. 2013. Dicerapanorpa, a new genus of East Asian Panorpidae (Insecta: Mecoptera: Panorpidae) with descriptions of two new species. Journal of Natural History 47: 1019-1046. https://doi.org/10.1080/00222933.2012.752540

Zhong W., Ding G. \& Hua B.Z. 2015. The role of male's anal horns in copulation of a scorpionfly. Journal of Zoology 295: 170-177. https://doi.org/10.1111/jzo.12194

Manuscript received: 9 December 2019

Manuscript accepted: 17 July 2020

Published on:1 September 2020

Topic editor: Nesrine Akkari

Section editor Helen M. Barber-James

Desk editor: Radka Rosenbaumová

Printed versions of all papers are also deposited in the libraries of the institutes that are members of the EJT consortium: Muséum national d'histoire naturelle, Paris, France; Meise Botanic Garden, Belgium; Royal Museum for Central Africa, Tervuren, Belgium; Royal Belgian Institute of Natural Sciences, Brussels, Belgium; Natural History Museum of Denmark, Copenhagen, Denmark; Naturalis Biodiversity Center, Leiden, the Netherlands; Museo Nacional de Ciencias Naturales-CSIC, Madrid, Spain; Real Jardín Botánico de Madrid CSIC, Spain; Zoological Research Museum Alexander Koenig, Bonn, Germany; National Museum, Prague, Czech Republic. 